\title{
Identification of miR-130b as an oncogene in renal cell carcinoma
}

\author{
YIFAN LI ${ }^{1-3}$, DUQUN CHEN ${ }^{1-3}$, YUCHI LI $^{3}$, LU JIN ${ }^{1-3}$, JIAJU LIU $^{1,2,4}$, ZHENGMING SU $^{1,2,4}$, ZHENGYU QI $^{2}$, \\ MIN SHI $^{2}$, ZHIMAO JIANG ${ }^{2}$, YAOTING GUI ${ }^{2}$, SHANGQI YANG ${ }^{1,2}$, XIANGMING MAO ${ }^{1,2}$ and YONGQING LAI ${ }^{1,2}$ \\ ${ }^{1}$ Department of Urology, Peking University Shenzhen Hospital; \\ ${ }^{2}$ Guangdong and Shenzhen Key Laboratory of Male Reproductive Medicine and Genetics, Institute of Urology, \\ Peking University Shenzhen Hospital, Shenzhen PKU-HKUST Medical Center, Shenzhen, Guangdong 518036; \\ ${ }^{3}$ Department of Urology, Anhui Medical University, Hefei, Anhui 230032; ${ }^{4}$ Department of Urology, \\ Shantou University Medical College, Shantou, Guangdong 515041, P.R. China
}

Received January 24, 2015; Accepted November 10, 2015

DOI: $10.3892 / \mathrm{mmr} .2015 .4744$

\begin{abstract}
Renal cell carcinoma (RCC) is the most common type of renal tumor, which has a poor prognosis. Improvements in understanding the underlying molecular biology of RCC has led to systemic treatments, which have markedly improved patient outcomes. Therefore, it is necessary and worthwhile to identify novel biomarkers for RCC. MicroRNAs (miRNAs) have been found to be important in a wide range of biological and pathological processes, including cell differentiation, migration, growth, proliferation, apoptosis and metabolism. Aberrant expression of miRNA-130b has previously been reported in tumors, however, its role in RCC remains to be elucidated. In the present study, the upregulation of miR-130b was observed in RCC tissues and cell lines using reverse transcription-quantitative polymerase chain reaction analysis, which was consistent with previous microRNA profiling in RCC. Furthermore, the effects of miR-130b on cell migration, proliferation and apoptosis were examined using a wound scratch assay, an MTT assay and flow cytometric analysis, respectively. The results demonstrated that the downregulation of miR-130b by a synthesized inhibitor inhibited cell migration, suppressed cell proliferation and induced RCC cell apoptosis. The present study was the first, to the best of our knowledge, to suggest that miR-130b may be a promising biomarker for diagnosis and a therapeutic target for the treatment of RCC. Further investigations are required to examine the roles and target genes of miR-130b in RCC.
\end{abstract}

Correspondence to: Dr Yongqing Lai or Dr Xiangming Mao, Department of Urology, Peking University Shenzhen Hospital, Shenzhen PKU-HKUST Medical Center, 1120 Lianhua Road, Shenzhen, Guangdong 518036, P.R. China

E-mail: yqlord@163.com

E-mail: 13691903635@126.com

Key words: microRNA, miR-130b, renal cell carcinoma, oncogene

\section{Introduction}

Kidney cancer is one of the most common types of malignancy in developed countries, and is increasing in developing countries $(1,2)$. Kidney cancer is more prevalent in males, and its estimated incidence and mortality rates in males are $\sim 111,100$ and 43,000 per year in developed countries (1). Renal cell carcinoma (RCC) accounts for $~ 90 \%$ of all renal tumors and $3.7 \%$ of all types of cancer in adults $(3,4)$. Clear cell RCC, which accounts for $80 \%$ of patients with RCC, is the most aggressive histological type of RCC, which has the highest rate of metastasis and the poorest prognosis (5). RCC is characterized by a lack of early-warning signs, protean clinical manifestations, and resistance to radiotherapy and chemotherapy (6). Developments in current understanding of the underlying molecular biology of renal cell carcinoma have led to systemic treatments, which have markedly improved patient outcomes (7). Therefore, it is necessary and worthwhile to identify novel biomarkers for RCC to improve diagnosis and treatment.

MicroRNAs (miRNAs), which regulate $50 \%$ of human genes by binding to the 3 '-untranslated regions (UTRs), are important in a wide range of biological and pathological processes, including cell differentiation, migration, growth, proliferation, apoptosis and metabolism (7-10). In tumorigenesis, miRNAs can function as oncogenes and tumor suppressors, and are predominantly dependent on their target genes (11). The aberrant expression of miRNAs has been reported between malignant and normal renal tissues, including between four histological subtypes of RCC, which suggest that miRNAs may provide a useful tool for diagnostic and prognostic improvements, and for the identification of predictive biomarkers (12). Specific miRNAs implicated in the pathogenesis of RCC include miRNA-23b, which targets the tumor suppressor gene, proline oxidase, which is unregulated in RCC, and functions as an oncogene by promoting proliferation and suppressing apoptosis. Therefore, decreasing the expression of miR-23b may be an effective method to inhibit kidney tumor growth (13).

Previously, studies have found that miR-130b is dysregulated in several types of human cancer, including chronic 
myeloid leukemia (14), T-cell leukemia (15), melanoma (16), head and neck cancer (17), thyroid cancer (18), pituitary cancer (19), ovarian cancer (20), endometrial cancer (21), colorectal cancer (22), gastric cancer (23), esophageal cancer (24), bladder cancer (25), prostate cancer (26), pancreatic cancer (27) and non-small cell lung cancer (28). Previous microarray chip studies have shown that the expression of miR-130b is significantly higher in RCC tissues, compared with adjacent normal tissues $(29,30)$. However, the expression of miR-130b in RCC has not been validated by quantitative polymerase chain reaction (qPCR) analysis, and the function of miR-130b in RCC requires further investigation. The aim of the present study was to validate the upregulation of miR-130b, and examine the effects of miR-130b on cellular migration, proliferation and apoptosis in RCC. The present study indicated that miR-130b is a potential biomarker for early diagnosis and a therapeutic target for the treatment of RCC.

\section{Materials and methods}

Cell lines and transfection. Human RCC cell lines (786-O and ACHN) and the 293T normal human embryo kidney cell line, were obtained from Guangdong and Shenzhen Key Laboratory of Male Reproductive Medicine and Genetics (Shenzhen, China), and were cultured in Dulbecco's modified Eagle's medium (DMEM; Thermo Fisher Scientific, Inc., Waltham, MA, USA), containing $10 \%$ fetal bovine serum (Gibco; Thermo Fisher Scientific, Inc.) and $1 \%$ antibiotics $(100 \mu / \mathrm{ml}$ penicillin and $100 \mathrm{mg} / \mathrm{ml}$ streptomycin sulfates; Gibco). All cells were incubated at $37^{\circ} \mathrm{C}$ in a humidified chamber containing $5 \%$ $\mathrm{CO}_{2}$. The 786-O, ACHN and 293T cells $\left(4 \times 10^{5}\right.$ cells/well $)$ were plated into 6-well plates (BD Biosciences, Franklin Lakes, NJ, USA) with three replicate wells, respectively. Total RNA, including miRNA, was extracted using an miRneasy Mini kit (Qiagen, Valencia, CA, USA) following harvesting of cells with trypsin.

In order to downregulate the expression of miR-130b in the cells, an miRNA oligonucleotide was chemically synthesized by GenePharma Company, Ltd. (Shanghai, China). The sequences were as follows: hsa-miR-130b inhibitor, 5'-AUGCCCUUU CAUCAUUGCACUG-3'; and hsa-miR-130b inhibitor negative control (NC), 5'-CAGUACUUUUGUGUAGUACAA-3'.

Clinical specimens. Paired clinical specimens (size, $0.5 \times 0.5 \times 0.5 \mathrm{~cm}^{3}$ ) of fresh RCC and adjacent normal tissues (located $2.0 \mathrm{~cm}$ outside of the visible RCC lesions), were obtained from 42 patients with RCC from the Department of Urology, Peking University Shenzhen Hospital (Shenzhen, China) between September 2012 and November 2014. Written informed consent was obtained from all patients, and the collection and use of the samples included in the present study were reviewed and approved by the ethics committee of the Peking University Shenzhen Hospital (Shenzhen, China). Once dissected, all fresh samples were immersed in RNAlater (Qiagen), frozen in liquid nitrogen and then stored at $-80^{\circ} \mathrm{C}$. The clinicopathological information of the patients is presented in Table I. Total RNA, including miRNA, was extracted from all tissue specimens using an miRneasy Mini kit (Qiagen, Valencia, CA, USA).
RNA purification and reverse-transcription $q P C R(R T-q P C R)$. Tissue samples were homogenized in $1 \mathrm{ml}$ TRIzol reagent (Invitrogen; Thermo Fisher Scientific) per $100 \mathrm{mg}$ of tissue using a power homogenizer (Tiangen Biochemical Science and Technology Co., Ltd., Beijing, China). Subsequently, homogenates were incubated for $5 \mathrm{~min}$ at room temperature to permit the complete dissociation of nucleoprotein complexes. Subsequent to vigorous manual agitation for $15 \mathrm{sec}$, samples were centrifuges at $12,000 \mathrm{x}$ g for $15 \mathrm{~min}$ at $4^{\circ} \mathrm{C}$. The total RNA, which was extracted from the tissues and cells, was purified using an RNeasy ${ }^{\circledR}$ Maxi kit (Qiagen), according to the manufacturer's protocol. The RNA samples with 260/280 ratios of 1.8-2.0 were used for further experiments. A total of $1 \mu \mathrm{g}$ total RNA was reverse transcribed into cDNA using an miScript II RT kit (Qiagen).

The expression levels of miR-130b were analyzed using an miScriptSYBR ${ }^{\circledR}$ green PCR kit (Qiagen) using the Roche lightcycler 480 Real-Time PCR system (Roche Diagnostics GmbH, Mannheim, Germany). The 20- $\mu 1$ reaction mixture contained $10 \mu \mathrm{l} 2 \mathrm{X}$ QuantiTect SYBR Green PCR Master mix, $2 \mu \mathrm{l}$ 10X miScript Universal Primer, $0.4 \mu 1$ specific miRNA primer, $1 \mu \mathrm{l}$ cDNA template and RNase-free water. The thermocycling steps were $95^{\circ} \mathrm{C}$ for $15 \mathrm{~min}$, followed by 40 cycles of $94^{\circ} \mathrm{C}$ $15 \mathrm{sec}, 55^{\circ} \mathrm{C}$ for $30 \mathrm{sec}$ and $72^{\circ} \mathrm{C}$ for $30 \mathrm{sec}$. U6 was used as an endogenous control to normalize the data. The mRNA expression levels were presented as the fold difference relative to U6, which was based on the relative quantification equation $\left(2^{-\Delta \Delta \mathrm{Cq}}\right): \Delta \Delta \mathrm{Cq}=\left(\right.$ meanCq $_{\text {tumor }}-$ meanCq $\left.\mathrm{q}_{\text {control }}\right)-($ meanCqnormal - meanCq $\mathrm{q}_{\text {control }}$ (32). The sequence of the miR-130b forward primer was 5'-CAGTGCAATGATGAAAGGGCAT-3' and the reverse primer was universal primer, provided in the miScriptSYBR ${ }^{\circledR}$ green PCR kit (Qiagen). The primer sequences of U6 were forward 5'-CTCGCTTCGGCAGCACA-3' and revers 5'-ACGCTTCACGAATTTGCGT-3'.

Wound healing assay. A wound healing assay was performed to evaluate the migratory ability of the 786-O and ACHN cells in vitro. The $786-\mathrm{O}$ or ACHN cells $\left(\sim 3 \times 10^{5} /\right.$ dish $)$ were seeded into 12-well dishes and cultured for $24 \mathrm{~h}$, prior to being transfected with 100 pmol of either the miR-130b inhibitor or the negative control using Lipofectamine ${ }^{\circledR} 2000$ (Invitrogen; Thermo Fisher Scientific). At 6 h post-transfection, a sterile $200 \mu \mathrm{l}$ pipette tip was used to make a scratch through the cell layer. The cells were then rinsed with phosphate-buffered saline (PBS) and cultured in serum-free DMEM at $37^{\circ} \mathrm{C}$. Images of the scratches were captured using a digital camera system, 0,24 and $48 \mathrm{~h}$ following the introduction of the scratches. The relative migratory distances (\%) were measured using an MIAS-2000 computer image analysis system (Leica Microsystems GmbH, Wetzlar, Germany), and the experiments were performed in triplicate and repeated at least three times.

MTT assay. An MTT assay was used to analyze the cell proliferation in the cell groups. The 786-O or ACHN cells $(\sim 5,000$ cells $)$ were plated into each well of a 96-well, plate with five replicate wells for each condition. Each well was transfected with 5 pmol miR-130b inhibitor or negative control, and measurements were obtained at $0,24,48$ or $72 \mathrm{~h}$ post-transfection. Blank control wells were also included, which contained DMEM only. Prior to the measurement, $20 \mu \mathrm{l}$ MTT 
Table I. Clinicopathological characteristics of patients with renal cell carcinoma.

\begin{tabular}{lc}
\hline Characteristic & Cases (n) \\
\hline Mean age (range; years) & $53(29-72)$ \\
Gender & \\
Male/female & $28 / 14$ \\
Histological type & $36 / 6$ \\
Clear cell/papillary & \\
pT-stage & $24 / 16 / 2$ \\
T1/T2/ T3+T4 & \\
Fuhrman grade & $14 / 18 / 7 / 3$ \\
I/II/III/IV & \\
AJCC clinical stages & $24 / 15 / 3$ \\
I/II/III+IV & \\
\hline
\end{tabular}

pT, primary tumor; AJCC, American Joint Committee on Cancer.

( $5 \mathrm{mg} / \mathrm{ml}$; Sigma-Aldrich, St. Louis, MO, USA) was added to each well, and the 96 -well plates were incubated at $37^{\circ} \mathrm{C}$ in a humidified chamber containing $5 \% \mathrm{CO}_{2}$ for $6 \mathrm{~h}$. Following incubation, the MTT medium mixtures were discarded and $120 \mu 1$ dimethyl sulphoxide (DMSO; Sigma-Aldrich) was added. Following agitation for $30 \mathrm{~min}$ at room temperature, the absorbance was measured using an ELISA microplate reader (Model 680; Bio-Rad Laboratories, Inc., Hercules, CA, USA) at a wavelength of $490 \mathrm{~nm}$ (with $630 \mathrm{~nm}$ as the reference wavelength).

Cell apoptosis assay. Enumeration of the rate of apoptosis of the cells was performed by staining with fluorescein isothiocyanate (FITC)-conjugated Annexin V and propidium iodide (PI), obtained from Invitrogen (Thermo Fisher Scientific, Inc.) using flow cytometry (Epics Xl-4, Beckman Coulter, Brea, CA, USA). The $786-\mathrm{O}$ or ACHN cells $\left(\sim 3 \times 10^{5}\right)$ were plated in each well of 6-well plates for the cell apoptosis assay. The cells were transfected with 200 pmol of either miR-130b inhibitor or the negative control for $6 \mathrm{~h}$. At $48 \mathrm{~h}$ post-transfection, the cells, including floating cells, were harvested, washed twice with $4^{\circ} \mathrm{C}$ PBS and resuspended in $100 \mu 11 \mathrm{X}$ binding buffer $[10 \mathrm{mM}$ 4-(2-hydroxyethyl)-1-piperazineethanesulfonic acid, $140 \mathrm{mM}$ $\mathrm{NaCl}, 2.5 \mathrm{mM} \mathrm{CaCl}_{2}$, pH 7.4; Invitrogen] at a concentration of at least $3 \times 10^{6}$ cells per ml. This suspension $(100 \mu \mathrm{l})$ was stained with $5 \mu \mathrm{l}$ of Annexin V-FITC and $5 \mu \mathrm{l}$ PI for $15 \mathrm{~min}$ at room temperature in the dark. Following the addition of $400 \mu 1$ binding buffer to each tube, the cells were analyzed using flow cytometry. Each experiment was performed at least three times.

Statistical analysis. All data are presented as the mean \pm standard deviation of three independent experiments. Statistical analyses were performed using the SPSS 19.0 statistical software package (IBM SPSS, Armonk, NY, USA). Statistical significance was determined using Student's t-test. For comparison of the expression levels of miR-130b in matched tumor and adjacent normal samples, a paired t-test was used.
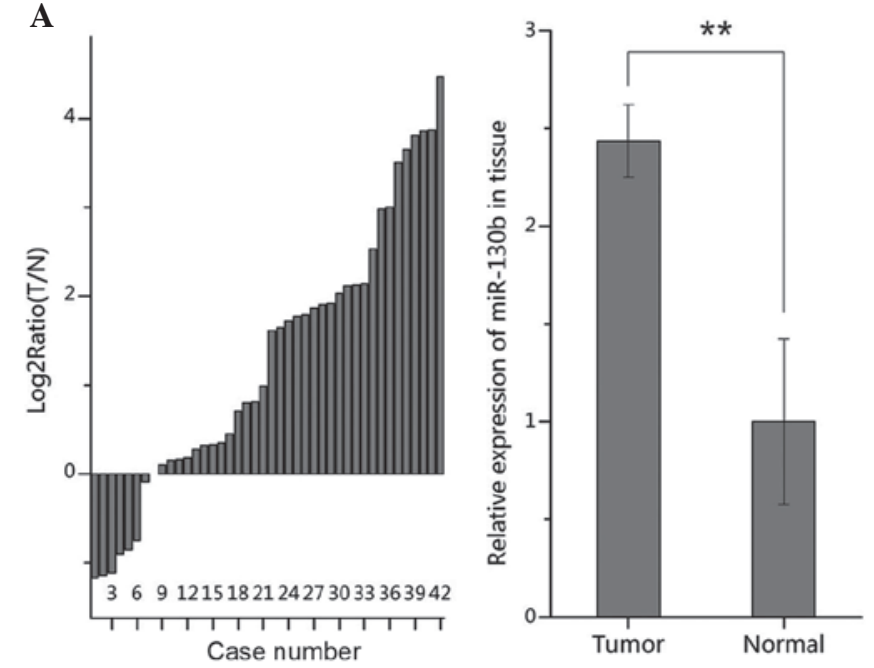

B

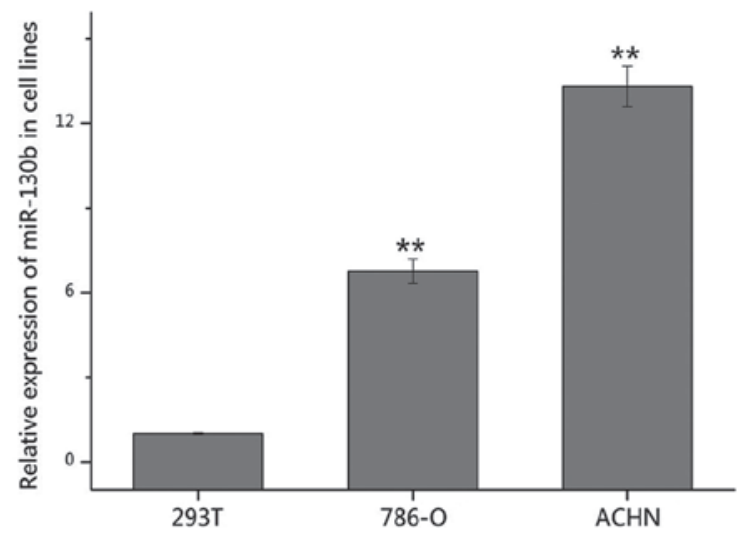

Figure 1. (A) Expression levels of miR-130b in 42 paired RCC tissues and adjacent normal tissues. Log 2 ratios of the expression of miR-130b in 42 paired RCC (T) tissues to normal (N) kidney tissues, and the relative expression of miR-130b in the RCC (tumor) and normal tissues. (B) Expression levels of miR-130b in the 786-O and ACHN RCC cell lines, and the normal human embryo kidney cell line (293T). Data are presented as the mean \pm standard deviation of three independent experiments. ${ }^{* *} \mathrm{P}<0.01$, vs. $293 \mathrm{~T}$ cells. RCC, renal cell carcinoma; $\mathrm{miR}$, microRNA.

$\mathrm{P}<0.05$ was considered to indicate a statistically significant difference.

\section{Results}

Expression of miR-130b is upregulated in RCC tissues and cells. To confirm the expression of miR-130b in RCC, the present study used RT-qPCR to quantify and compare the expression levels of miR-13b between the $42 \mathrm{RCC}$ and paired adjacent normal tissue samples, and between the 786-O and ACHN RCC cell lines and 293T cell line. As shown in Fig. 1A, the expression of miR-130b was significantly increased (35/42) in the tumor tissues, compared with the normal tissue samples $(\mathrm{P}<0.01)$. It was also revealed that the expression levels of miR-130b were significantly upregulated in the 786-O and ACHN cells, compared with the 293T cells (Fig. 1B). These results suggested that miR-130b acts as an oncogene in RCC.

Validation of the suppression of $m i R-130 b$ by RT-qPCR. To further investigate the function of miR-130b in RCC, the high 
A

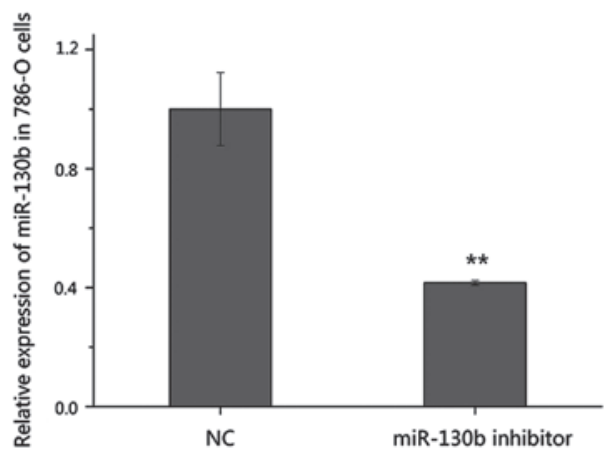

B

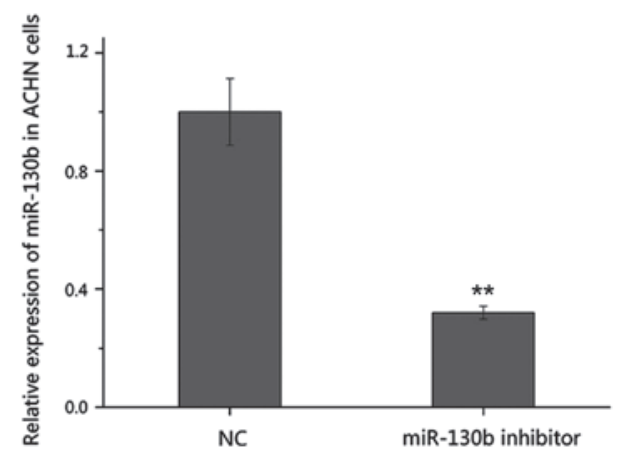

Figure 2. Validation of cell transfection efficiency. The relative expression levels of miR-130b were determined in the (A) 786-O and (B) ACHN cells transfected with miR-130b inhibitor or NC. Data are presented as the mean \pm standard deviation of three independent experiments. ${ }^{* *} \mathrm{P}<0.01$, vs. NC. miR, microRNA; NC, negative control.
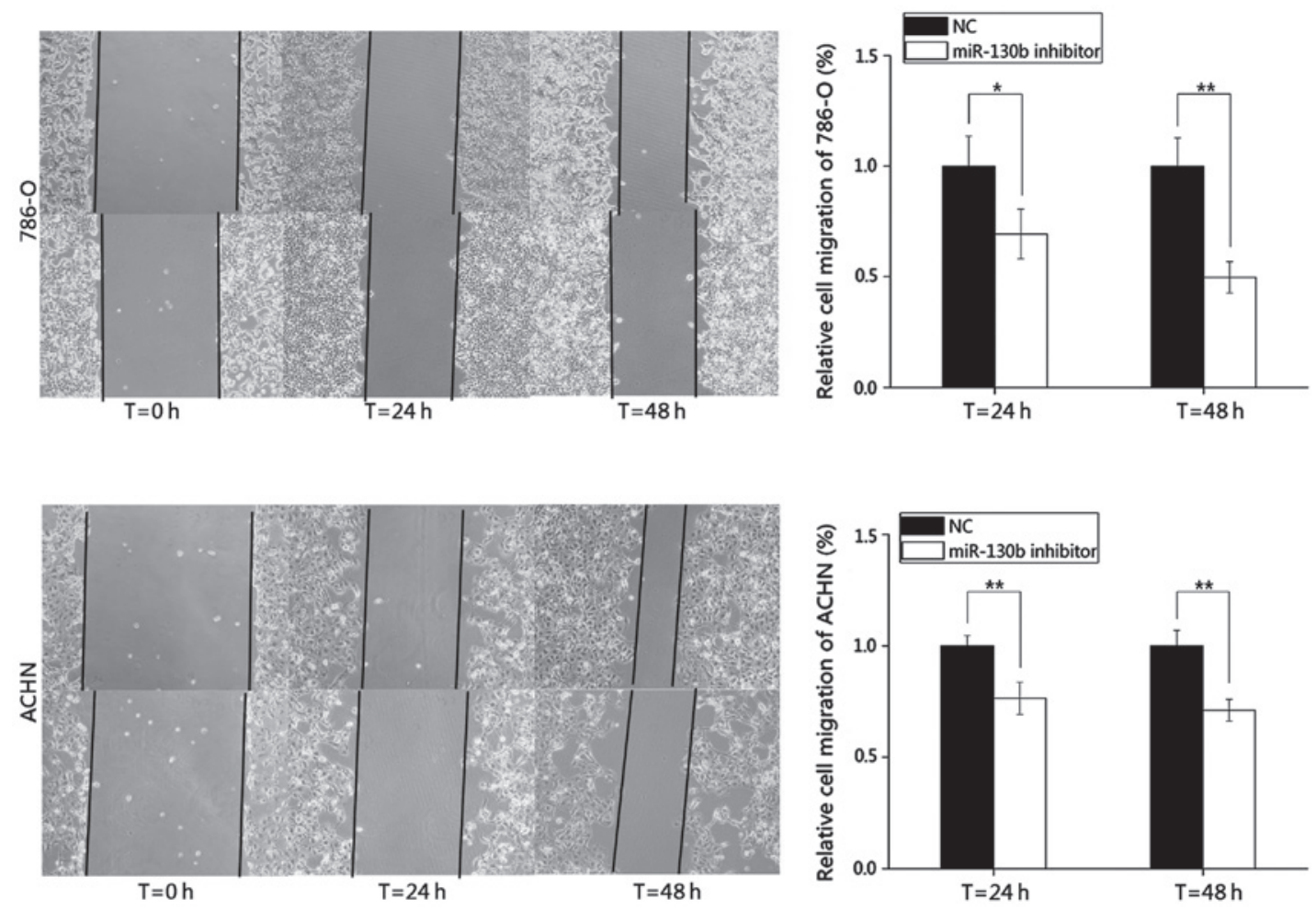

Figure 3. Wound healing assay determination of the migration of 786-O and ACHN cells following transfection with miR-130b inhibitor or NC after 24 and $48 \mathrm{~h}$. Data are presented as the mean \pm standard deviation of three independent experiments. ${ }^{~} \mathrm{P}<0.05$ and ${ }^{* *} \mathrm{P}<0.01$, vs. NC. miR, microRNA; NC, negative control; T, time.

expression level of miR-130b was suppressed in the present study using a chemically synthesized miR-130b inhibitor. The silencing efficiency of the miR-130b inhibitor was validated using RT-qPCR $48 \mathrm{~h}$ post-transfection. As shown in Fig. 2, the expression of miR-130b decreased by $58.4 \%$ in the $786-\mathrm{O}$ cells and by $68.0 \%$ in the ACHN cells transfected with the inhibitor, compared with the cells transfected with the negative control.

A reduction in the expression of $m i R-130 b$ inhibits $R C C$ cell migration. In the present study, wound healing assays were performed to observe the function of miR-130b in cell migration. Images of the scratch wounds were captured 0, 24 and $48 \mathrm{~h}$ following transfection using a digital camera system (Fig. 3). The results demonstrated that the migratory distances of the cells transfected with the miR-130b inhibitor after 24 and $48 \mathrm{~h}$ were markedly inhibited by 30.66 and $50.29 \%$ in the $786-\mathrm{O}$ cells, and by 23.54 and $28.92 \%$ in the ACHN cells, respectively, compared with the negative control group. These results indicated that the reduction in the expression of miR-130b inhibited the migration of the RCC cells.

Downregulation of miR-130b suppresses RCC cell proliferation. The potential effect of miR-130b on the proliferation of RCC cells was determined using MTT assays. The miR-130b inhibitor and negative control groups were measured at 0 , 24,48 and $72 \mathrm{~h}$ post-transfection. The statistical analyses of the optical density values demonstrated that the proliferation of the 786-O cells was inhibited at 24,48 and $72 \mathrm{~h}$ by 12.34 $(\mathrm{P}<0.01), 19.15(\mathrm{P}<0.05)$ and $34.81 \%(\mathrm{P}<0.01)$, respectively. In 

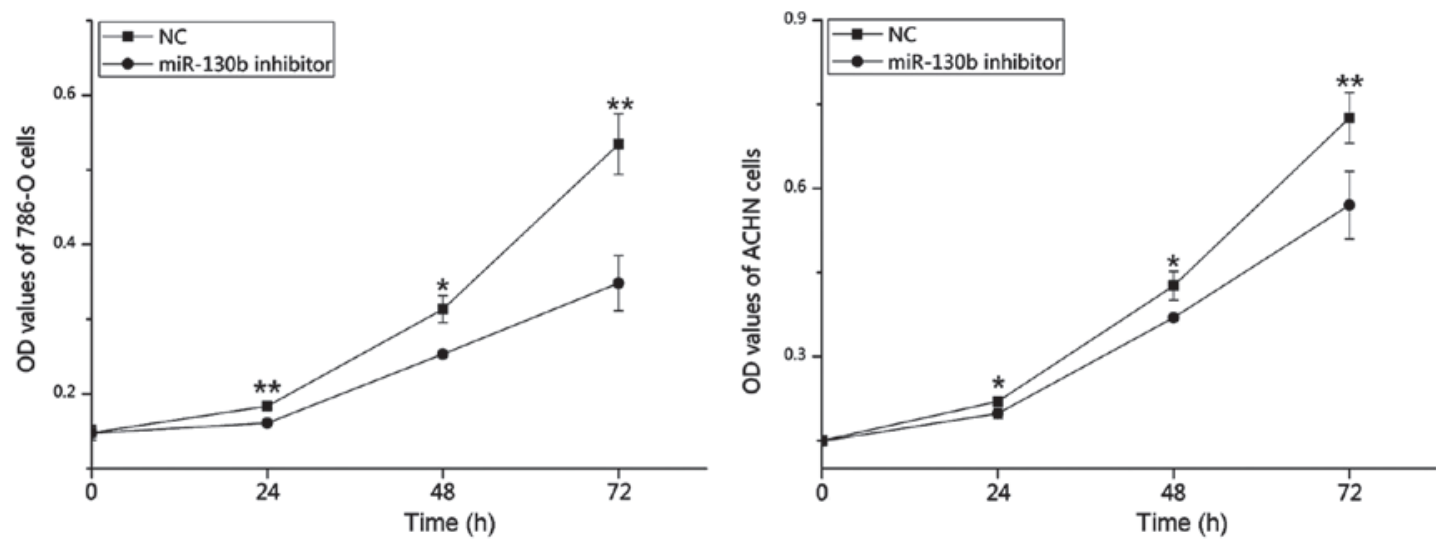

Figure 4. Proliferation of 786-O and ACHN, were measured using an MTT assay at different time intervals following transfection. Data are presented as the mean \pm standard deviation of three independent experiments. ${ }^{*} \mathrm{P}<0.05$ and ${ }^{* *} \mathrm{P}<0.01$, vs. NC. miR, microRNA; NC, negative control; OD, optical density.
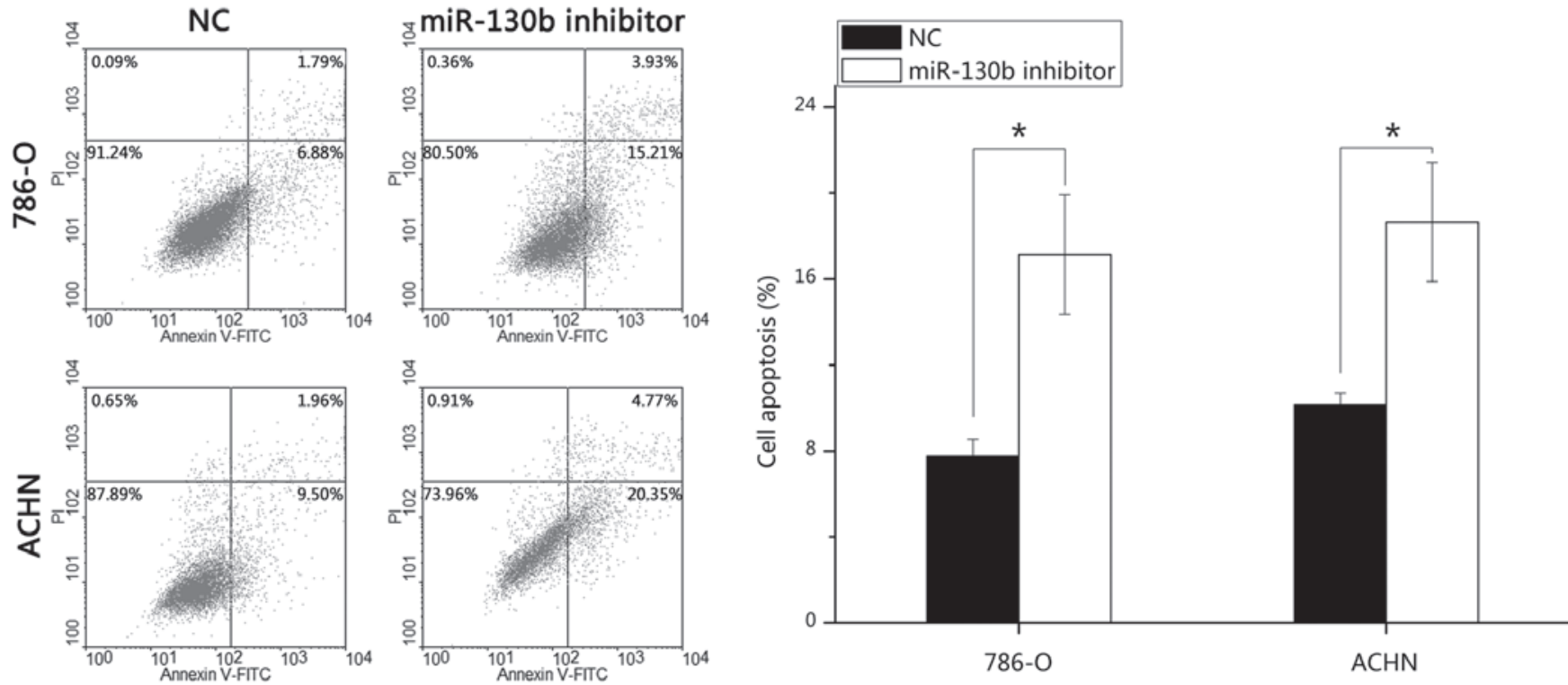

Figure 5. Percentages of apoptosis in the 786-O and ACHN cell lines, measured using flow cytometry. The upper left quadrant represents cell debris and damaged cells. The upper right quadrant represents late apoptotic cells and dead cells. The lower left quadrant represents normal cells. The lower right quadrant represents early apoptotic cells and the percentage of the lower right quadrant is the apoptotic rate which was compared between the samples. Data are presented as the mean \pm standard deviation of three independent experiments. " $\mathrm{P}<0.05$, vs. NC. miR, microRNA; NC, negative control; FITC, fluorescein isothiocyanate; PI, propidium iodide.

addition, the proliferation of the ACHN cells decreased by 9.56 $(\mathrm{P}<0.05), 13.80(\mathrm{P}<0.05)$ and $23.08 \%(\mathrm{P}<0.01)$ at 24,48 and $72 \mathrm{~h}$ post-transfection, respectively. These results suggested that the miR-130b inhibitor reduced the growth of the 786-O and ACHN cells, compared with the negative control inhibitor (Fig. 4).

miR-130b inhibitor induces RCC cell apoptosis. To determine the potential role of miR-130b on the apoptosis of RCC cells, FITC-conjugated Annexin V and PI assays were performed. Following transfection of the cells with the miR-130b inhibitor or negative control for $48 \mathrm{~h}$, the 786-O and ACHN cells were harvested, stained and analyzed. The results demonstrated that the average early apoptotic rates of the 786-O cells transfected with the miR-130b inhibitor and the negative control were 17.13 and $7.77 \%$, respectively $(\mathrm{P}<0.05)$, and the average apoptotic rates of the ACHN cells were 18.65 and $10.13 \%$, respectively $(\mathrm{P}<0.05)$. These data indicated that the miR-130b inhibitor promoted RCC cell apoptosis (Fig. 5).

\section{Discussion}

The development of cancer involves the overexpression of oncogenes and silencing of tumor suppressor genes. The well-known dysregulated signal transduction pathways in RCC tumorigenesis, including the anti-oncogene, von Hippel Lindau (VHL) and oncogene, vascular endothelial growth factor (VEGF) (13). miRNAs are a class of small non-coding RNA, which exert their function by targeting specific genes, including hypoxia-inducible factor, mammalian target of rapamycin, VEGF and VHL, which are key molecules involved in the initiation and development of clear cell RCC, through translation inhibition or the induction of mRNA degradation $(32,33)$. For example, miR-141 and 200c, which are downregulated in 
RCC, affect epithelial-mesenchymal transition (EMT) via zinc finger homeobox 1b-mediated repression of E-cadherin (34). In addition, the increased expression of miR-29b, due to ectopic expression of VHL, inhibits the protein expression of TIs11B, a known negative regulator of VEGF (35), suggesting that miR-29b possesses oncogenic activity. By targeting different important genes, affecting cellular proliferation, differentiation, migration and apoptosis, miRNAs have been shown to be crucial in carcinogenesis and cancer progression.

miR-130b has been reported to be dysregulated in several types of cancer (14-28), in which the expression of miR-130b is either upregulated or downregulated. miR-130b is either upregulated and function as an oncogene by targeting tumor suppressor genes, or downregulated and identified as an anti-oncogene by decreasing oncogenes.

Chronic myeloid leukaemia (CML) is a myeloproliferative disorder, which is characterized by the expression of the oncoprotein, Bcr-Abl kinase. miRNA-130a/b are regulated by BCR-ABL and downregulate the expression of the tumor suppressive gene, CCN3 (36). miR-130b is consistently upregulated in human T-cell leukemia virus 1-transformed cells, targeting the tumor suppressor protein, tumor protein 53-induced nuclear protein 1 (15). Leone et al reported that the levels of miR-130b are markedly reduced in pituitary adenomas, and that the overexpression of miR-130b inhibits cell proliferation, arresting cells in the G1 and G2 phases of the cell cycle by targeting cyclin A2 (19). In endometrial cancer, the overexpression of miR-130b and loss of DICER1 induced abnormal expression of EMT-associated genes, which constitute a loop regulation of the miR-130b-DICER1-EMT axis (21). In colorectal cancer, Colangelo et al (22) demonstrated that the upregulation of miR-130b exhibits clinical relevance, as it is linked to advanced cases of colorectal cancer, poor patient prognosis, and molecular features of enhanced EMT and angiogenesis by directly targeting peroxisome proliferator-activated receptor $\gamma(\operatorname{PPAR} \gamma)$ in vitro and in vivo. From another perspective, miR-130b significantly decreases cell migration and invasion by downregulating integrin $\beta 1$ (37). In gastric cancer, the overexpression of miR-130b increases cell viability, reduces cell death and decreases the expression of B cell lymphoma-2-interacting mediator of cell death in transforming growth factor- $\beta$ mediated apoptosis, subsequent to the downregulation in the protein expression of Runt-related transcription factor 3 (23). However, miR-130b is significantly downregulated and exerts a suppressive effect in prostate and pancreatic cancer metastasis through the downregulation of matrix metalloproteinase 2 and signal transducer and activator of transcription 3 , respectively $(26,27)$.

However, the expression and function of miR-130b in RCC have not been reported previously. Previous miRNA profiling studies have shown the upregulation of miR-130b in RCC $(29,30)$. In the present study, the increased expression of miR-130b as validated in RCC tissues and 786-O and ACHN RCC cell lines, compared with adjacent normal tissues and 293 cell lines, using RT-qPCR. In addition, the downregulation of miR-130b through synthesized miR-130b inhibitor was found to weaken cellular migration and proliferation, and induce apoptosis in the 786-O and ACHN cells, which was shown in the wound-healing, MTT and apoptosis assays, respectively. These results suggested that miR-130b may be characterized as an oncogene in RCC by regulating cell migration, proliferation and apoptosis.

It appears contradictory that miR-130b was identified as an oncogene in certain types of cancer, but as a tumor suppressor gene in others. This inconsistency may be explained by imperfect binding of the miRNA to the 3'-UTR in mammals (8). Due to imperfect complementarity, a single miRNA can potentially regulate hundreds of genes, including oncogenes and tumor suppressor genes, and a specific gene can be regulated by several miRNAs. In addition, the expression pattern of genes and miRNAs is tissue-, organ- and time-specific. Therefore, miR-130b is upregulated in CML, endometrial cancer, colorectal cancer and gastric cancer, but reduced in pituitary adenoma, prostate and pancreatic cancer. Even in the same type of cancer, by targeting different genes, a specific miRNA can function differently. For example, in colorectal cancer, miR-130b decreases cell migration and invasion by decreasing intergrin $\beta 1$ (37), but promotes cell proliferation, EMT and angiogenesis by targeting PPAR $\gamma(22)$.

To the best of our knowledge, the results of the present study provide novel insight into the roles and possible mechanisms underlying the effects of miR-130b in the occurrence and development of RCC. miR-130b was significantly upregulated in human RCC tissues and cell lines, and was observed to function as an oncogene by affecting cell migration, proliferation and apoptosis in RCC cell lines. In addition, the data obtained in the present study suggest that miR-130b may be a promising biomarker for early diagnosis, and a therapeutic target for the treatment of RCC. Further investigations are required to define the roles and target genes of miR-130b in RCC and other types of cancer.

\section{Acknowledgements}

The present study was supported by the National Natural Science Foundation of China (no. 81101922), the Science and Technology Development Fund Project of Shenzhen (nos. CYJ20130402114702124 and JCYJ20150403091443329) and the fund of Guangdong Key Medical Subject.

\section{References}

1. Jemal A, Bray F, Center MM, Ferlay J, Ward E and Forman D: Global cancer statistics. CA Cancer J Clin 61: 69-90, 2011.

2. Chen W, Zheng R, Zhang S, Zhao P, Zeng H, Zou X and He J: Annual report on status of cancer in China, 2010. Chin J Cancer Res 26: 48-58, 2014.

3. Tavani A and La Vecchia C: Epidemiology of renal-cell carcinoma. J Nephrol 10: 93-106, 1997.

4. National Cancer Institute: Surveillance, Epidemiology and End Results Program. SEER Stat Fact Sheets: Kidney and Renal Pelvis Cancer. http://seer.cancer.gov/statfacts/html/kidrp.html. Accessed December 12, 2015.

5. Rini BI, Campbell SC and Escudier B: Renal cell carcinoma. Lancet 373: 1119-1132, 2009.

6. Motzer RJ, Bander NH and Nanus DM: Renal-cell carcinoma. N Engl J Med 335: 865-875, 1996.

7. Huntzinger E and Izaurralde E: Gene silencing by microRNAs: Contributions of translational repression and mRNA decay. Nat Rev Genet 12: 99-110, 2011.

8. Bartel DP: MicroRNAs: Target recognition and regulatory functions. Cell 136: 215-233, 2009.

9. Krol J, Loedige I and Filipowicz W: The widespread regulation of microRNA biogenesis, function and decay. Nat Rev Genet 11: 597-610, 2010. 
10. Carthew RW and Sontheimer EJ: Origins and Mechanisms of miRNAs and siRNAs. Cell 136: 642-655, 2009.

11. Fendler A, Stephan C, Yousef GM and Jung K: MicroRNAs as regulators of signal transduction in urological tumors. Clin Chem 57: 954-968, 2011.

12. Rydzanicz M, Wrzesiński T, Bluyssen HA and Wesoły J: Genomics and epigenomics of clear cell renal cell carcinoma: Recent developments and potential applications. Cancer Lett 341: 111-126, 2013

13. Liu W, Zabirnyk O, Wang H, Shiao YH, Nickerson ML, Khalil S, Anderson LM, Perantoni AO and Phang JM: MiR-23b targets proline oxidase, a novel tumor suppressor protein in renal cancer. Oncogene 29: 4914-4924, 2010.

14. Ferreira AF, Moura LG, Tojal I, Ambrósio L, Pinto-Simões B, Hamerschlak N, Calin GA, Ivan C, Covas DT, Kashima S and Castro FA: ApoptomiRs expression modulated by BCR-ABL is linked to CML progression and imatinib resistance. Blood Cells Mol Dis 53: 47-55, 2014.

15. Yeung ML, Yasunaga J, Bennasser Y, Dusetti N, Harris D, Ahmad N, Matsuoka M and Jeang KT: Roles for microRNAs, miR-93 and miR-130b and tumor protein 53-induced nuclear protein 1 tumor suppressor in cell growth dysregulation by human T-cell lymphotrophic virus 1. Cancer Res 68: 8976-8985, 2008

16. Sand M, Skrygan M, Sand D, Georgas D, Gambichler T, Hahn SA, Altmeyer P and Bechara FG: Comparative microarray analysis of microRNA expression profiles in primary cutaneous malignant melanoma, cutaneous malignant melanoma metastases and benign melanocytic nevi. Cell Tissue Res 351: 85-98, 2013.

17. Chen Z, Jin Y, Yu D, Wang A, Mahjabeen I, Wang C, Liu X and Zhou X: Down-regulation of the microRNA-99 family members in head and neck squamous cell carcinoma. Oral Oncol 48: 686-691, 2012.

18. Dettmer MS, Perren A, Moch H, Komminoth P, Nikiforov YE and Nikiforova MN: MicroRNA profile of poorly differentiated thyroid carcinomas: New diagnostic and prognostic insights. J Mol Endocrinol 52: 181-189, 2014.

19. Leone V, Langella C, D'Angelo D, Mussnich P, Wierinckx A, Terracciano L, Raverot G, Lachuer J, Rotondi S, Jaffrain-Rea ML, et al: Mir-23b and miR-130b expression is downregulated in pituitary adenomas. Mol Cell Endocrinol 390: $1-7,2014$

20. Wang L, Zhu MJ, Ren AM, Wu HF, Han WM, Tan RY and Tu RQ: A ten-microRNA signature identified from a genome-wide microRNA expression profiling in human epithelial ovarian cancer. PLoS One 9: e96472, 2014.

21. Li BL, Lu C, Lu W, Yang TT, Qu J, Hong X and Wan XP: MiR-130b is an EMT-related microRNA that targets DICER1 for aggression in endometrial cancer. Med Oncol 30: 484, 2013.

22. Colangelo T, Fucci A, Votino C, et al: MicroRNA-130b promotes tumor development and is associated with poor prognosis in colorectal cancer. Neoplasia 15: 1086-1099, 2013.

23. Lai KW, Koh KX, Loh M, Tada K, Subramaniam MM, Lim XY, Vaithilingam A, Salto-Tellez M, Iacopetta B and Ito Y, Soong R; Singapore Gastric Cancer Consortium: MicroRNA-130b regulates the tumour suppressor RUNX3 in gastric cancer. Eur J Cancer 46: 1456-1463, 2010.
24. Zhao BS, Liu SG, Wang TY, Ji YH, Qi B, Tao YP, Li HC and $\mathrm{Wu} \mathrm{XN}$ : Screening of microRNA in patients with esophageal cancer at same tumor node metastasis stage with different prognoses. Asian Pac J Cancer Prev 14: 139-143, 2013.

25. Ratert N, Meyer HA, Jung M, Lioudmer P, Mollenkopf HJ, Wagner I, Miller K, Kilic E, Erbersdobler A, Weikert S and Jung K: MiRNA profiling identifies candidate mirnas for bladder cancer diagnosis and clinical outcome. J Mol Diagn 15: 695-705, 2013.

26. Chen Q, Zhao X, Zhang H, Yuan H, Zhu M, Sun Q, Lai X, Wang Y, Huang J, Yan J and Yu J: MiR-130b suppresses prostate cancer metastasis through down-regulation of MMP2. Mol Carcinog 23: 22204, 2014

27. Zhao G, Zhang JG, Shi Y, Qin Q, Liu Y, Wang B, Tian K, Deng SC, Li X, Zhu S, et al: MiR-130b is a prognostic marker and inhibits cell proliferation and invasion in pancreatic cancer through targeting STAT3. PLoS One 8: e73803, 2013.

28. Mitra R, Edmonds MD, Sun J, Zhao M, Yu H, Eischen CM and Zhao Z: Reproducible combinatorial regulatory networks elucidate novel oncogenic microRNAs in non-small cell lung cancer. RNA 20: 1356-1368, 2014

29. Wulfken LM, Moritz R, Ohlmann C, Holdenrieder S, Jung V, Becker F, Herrmann E, Walgenbach-Brünagel G, von Ruecker A, Müller SC and Ellinger J: MicroRNAs in renal cell carcinoma: Diagnostic implications of serum miR-1233 levels. PLoS One 6: e25787, 2011

30. Wu X, Weng L, Li X, Guo C, Pal SK, Jin JM, Li Y, Nelson RA, Mu B, Onami SH, et al: Identification of a 4-microRNA signature for clear cell renal cell carcinoma metastasis and prognosis. PLoS One 7: e35661, 2012.

31. Livak KJ and Schmittgen TD: Analysis of relative gene expression data using real-time quantitative PCR and the 2(-Delta Delta C(T)) Method. Methods 25: 402-408, 2001.

32. Maher ER: Genomics and epigenomics of renal cell carcinoma. Semin Cancer Biol 23: 10-17, 2013.

33. Chow TF, Mankaruos M, Scorilas A, Youssef Y, Girgis A, Mossad S, Metias S, Rofael Y, Honey RJ, Stewart R, et al: The miR-17-92 cluster is over expressed in and has an oncogenic effect on renal cell carcinoma. J Urol 183: 743-751, 2010.

34. Nakada C, Matsuura K, Tsukamoto $Y$, Tanigawa $M$, Yoshimoto T, Narimatsu T, Nguyen LT, Hijiya N, Uchida T, Sato F, et al: Genome-wide microRNA expression profiling in renal cell carcinoma: Significant down-regulation of miR-141 and miR-200c. J Pathol 216: 418-427, 2008.

35. Sinha S, Dutta S, Datta K, Ghosh AK and Mukhopadhyay D Von Hippel-Lindau gene product modulates TIS11B expression in renal cell carcinoma: Impact on vascular endothelial growth factor expression in hypoxia. J Biol Chem 284: 32610-32618, 2009.

36. Suresh S, McCallum L, Lu W, Lazar N, Perbal B and Irvine AE: MicroRNAs $130 \mathrm{a} / \mathrm{b}$ are regulated by BCR-ABL and downregulate expression of CCN3 in CML. J Cell Commun Signal 5: 183-191, 2011.

37. Zhao Y, Miao G, Li Y, Isaji T, Gu J,Li J and Qi R: MicroRNA-130b suppresses migration and invasion of colorectal cancer cells through downregulation of integrin $\beta 1$ [corrected]. PLoS One 9: e87938, 2014. 